\title{
Carney Syndrome: A family no longer cursed
}

\author{
Samantha Gelman*, Andrew Benin, Rita Ishkhanian, Harjeet Singh, Jyotsna Sharma and Rajesh Gulati \\ *GME Department of Medicine, Riverside Community Hospital, Riverside, USA \\ *Corresponding author: Samantha Gelman, GME Department of Medicine, Riverside Community Hospital, Riverside, USA
}

\begin{tabular}{|c|c|}
\hline ARTICLE INFO & ABSTRACT \\
\hline 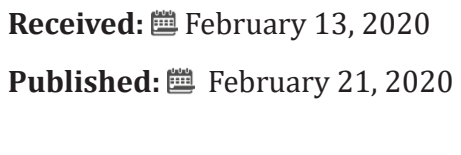 & $\begin{array}{l}\text { Citation: Samantha Gelman, Andrew Benin, Rita Ishkhanian, Harjeet Singh, Jyotsna } \\
\text { Sharma, Rajesh Gulati. Carney Syndrome: A family no longer cursed. Biomed J Sci \& Tech } \\
\text { Res 25(5)-2020. BJSTR. MS.ID.004266. }\end{array}$ \\
\hline
\end{tabular}

\section{Opinion}

Carney syndrome is a rare autosomal dominant condition characterized by a multitude of benign tumors both endocrine and non-endocrine in nature. It is also associated with various endocrinopathies as well as, spotty skin pigmentation. It has been seen in 150 cases worldwide and has a variable presentation making it a continuous diagnostic challenge. Here we present the $151^{\text {st }}$ known case of Carney syndrome. A 24-year-old male presented with a chief complaint of sharp right sided abdominal pain. The patient denied any personal medical history but noted a strong family history of Carney syndrome. He reported that his relatives had passed away from unexplained reasons that many attributed to cancers between the ages of thirty and forty. Physical exam findings were positive for abnormal facies, lentiginous skin pigmentation over the suprascapular region and face, as well as, evidence of broad shoulders. CT imaging was obtained and revealed a $6.8 \mathrm{~cm}$ $\mathrm{x} 4.5 \mathrm{~cm} \times 6.1 \mathrm{~cm}$ mixed hypo/hyperattenuating right lower medial pleural mass with possible truncation with the neural foramina at the T10-T11 region.

He also was found to have bilateral coarse intrastromal microcalcifications. MRI demonstrated complex solid and cystic circumscribed right sided lower thoracic paraspinal mass extending from the T9-T10 disc space level down to the T11-T12 disc space measuring $72 \times 54 \times 46.5 \mathrm{~mm}$. The patient was found to have an incidental arachnoid cyst that was stable on further imaging. Scrotal ultrasound showed extensive prominent microlithiasis in the bilateral testes. On the following day, his symptoms had selfresolved. Neurosurgery, vascular, cardiothoracic surgery and urology were consulted. A biopsy was done of the paraspinal mass that revealed a melanocytic schwannoma. Oncology was consulted and reported that the tumor has a benign course. Genetic testing in the maternal aunt was positive for PRKAR1A gene which is highly associated with Carney syndrome. Other workup for PTH, GH, LH, FSH, ACTH, Cortisol, TFTs, urine metanephros's, catecholamines, 5HIAA and ADH were unremarkable. The patient did have an elevated IGF-1 level corresponding to an associated endocrinopathy specifically, acromegaly.

The patient was discharged from the hospital with appropriate follow up for VATS procedure to remove the paraspinal mass. The patient will require annual echocardiograms to assess for myxoma given its high occurrence as well as, recurrence. Current research shows that Carney syndrome is associated with melanotic schwannomas. These patients are also at a higher risk for cardiac myxomas; however, the patient's transthoracic echocardiogram was unremarkable. Many of these patients have associated Sertoli cell testicular tumors, primary pigmented nodular adrenocortical disease, Cushing syndrome, among others. This case illustrates the importance of an appropriate history and physical exam. It also requires us to be able to diagnose conditions that are rare via genetic testing. In this case, family members have undergone genetic testing, but for years the family believed to be "cursed" and did not seek further workup. Recognition of this syndrome is critical to the institution of appropriate therapy. Further studies need to be done so that more cases can be diagnosed, and individuals can subsequently understand how this will affect life expectancy as well as, overall health.

\section{Acknowledgement}

This research was supported (in whole or in part) by HCA and/ or an HCA affiliated entity. The views expressed in this publication represent those of the author(s) and do not necessarily represent the official views of HCA or any of its affiliated entities. 
ISSN: 2574-1241

DOI: $10.26717 /$ BJSTR.2020.25.004266

Samantha Gelman. Biomed J Sci \& Tech Res

(c) (P) This work is licensed under Creative BY Commons Attribution 4.0 License

Submission Link: https://biomedres.us/submit-manuscript.php

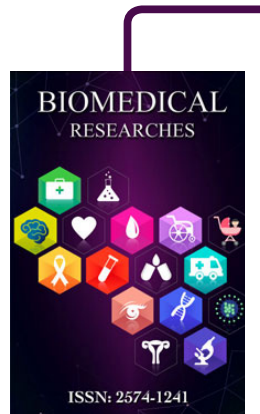

Assets of Publishing with us

- Global archiving of articles

- Immediate, unrestricted online access

- Rigorous Peer Review Process

- Authors Retain Copyrights

- Unique DOI for all articles

https://biomedres.us/ 